May $2002 \quad$ Volume $111 \quad$ Number 5

\title{
MEASUREMENT OF THE ELECTRICALLY EVOKED COMPOUND ACTION POTENTIAL VIA A NEURAL RESPONSE TELEMETRY SYSTEM
}

\author{
WAI KONG LAI, PHD \\ ZÜRICH, SWITZERLAND \\ JOACHIM MÜLLER-DEILE, MSC \\ KIEL, GERMANY
}

\author{
NORBERT DILLIER, PHD \\ ZÜRICH, SWITZERLAND \\ BENGT ALMQVIST, PHD \\ LUND, SWEDEN \\ MATTHIAS STECKER, PHD \\ FreIBURG, GERMANY
}

\author{
CAROLIN FROHNE, MSC \\ HANNOVER, GERMANY
}

ERNST VON WALLENBERG, PHD

BASEl, SWITZERLAND

The main aim of this study was to validate a new technique, neural response telemetry (NRT), for measuring the electrically evoked compound action potential in adult cochlear implant users via their Nucleus CI24M implant. Thirty-eight adults were evaluated with a variety of measurement procedures with the NRT software. Electrically evoked compound action potentials were obtained in 31 of the 38 adults $(81.6 \%)$ and in 132 of the 160 electrodes $(82.5 \%)$ tested. In addition to validating this technique, we also established a set of default clinical test parameters.

KEY WORDS - cochlear implant, electrically evoked compound action potential, neural response telemetry.

\section{INTRODUCTION}

Impedance and compliance telemetry is useful in assessing electrode function of most of the current cochlear implant systems. However, because of the variation in spiral ganglion cell survival associated with deafness, ${ }^{1}$ variation in performance across cochlear implant users remains unpredictable despite a fully functioning electrode array. Some clinical measure of peripheral neural function in addition to telemetric assessment of electrode function is a reasonable approach to addressing this issue. Such a measurement technique would need to be validated before considering its clinical implications.

In 1992, a bidirectional telemetry feature was implemented in the design of the Nucleus CI24M cochlear implant system ${ }^{2}$ that can be used to record electrically evoked compound action potentials (ECAPs). The action potentials that result from a stimulus applied on a given intracochlear electrode are recorded from a neighboring electrode, amplified, and then encoded for transmission via the radio frequency (RF) link back to the speech processor. Custom (neural response telemetry (NRT) software, written at the Department of Otorhinolaryngology, University Hospital of Zürich, communicates with the speech processor to capture, process, store, and display the measurement data on a host personal computer, as shown in Fig 1. The NRT software controls the parameters of the stimulus used to evoke the response being measured, as well as the parameters used to perform the recording.

The NRT software implements the masker-probe

Fig 1. Neural response telemetry (NRT) system comprising personal computer (PC) with installed NRT software and IF5 interface card, clinical processor control interface, SPrint speech processor, headset with coil for radio frequency (RF) transmission, and Nucleus CI24M implant including electrode array. Stimulation parameters transmitted via RF link from processor to implant are received and decoded (Rx Decode) and presented as stimulus (Stim) by implant. Evoked compound action potential is then recorded (Rec), and data are encoded for transmission (Tx Encode) back to implant over same RF link.

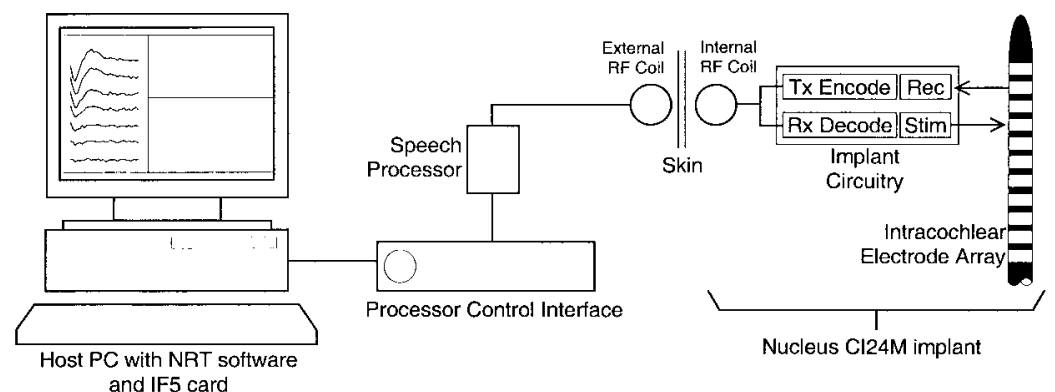

From the Department of Otorhinolaryngology, University Hospital, Zürich, Switzerland (Dillier, Lai), the Audiology Department, University Hospital, Lund, Sweden (Almqvist), and the Medical University of Hannover, Hannover (Frohne), the ENT Department, University of Kiel, Kiel (Müller-Deile), and the ENT Department, University of Freiburg, Freiburg (Stecker), Germany. Dr von Wallenberg is Clinical Technical Manager Europe for Cochlear AG, Basel, Switzerland. This work was supported by the Swiss National Foundation (grant 3200-047325.96) and a research grant from Cochlear AG, Basel.

CORRESPONDENCE — Norbert Dillier, PhD, Dept of Otorhinolaryngology, University Hospital, CH-8091 Zürich, Switzerland. 


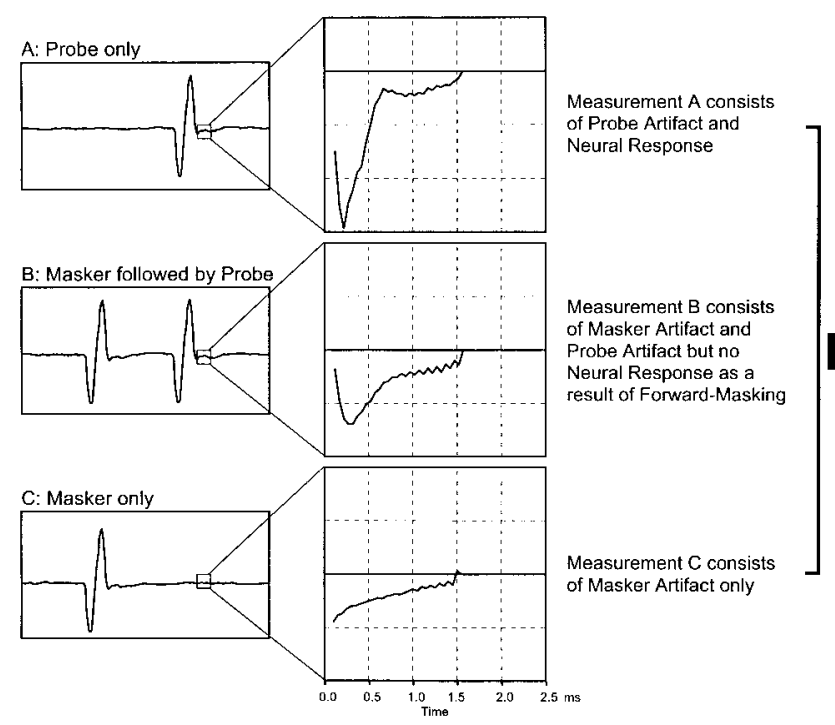

paradigm described by Brown et $\mathrm{al}^{3}$ that is illustrated in Fig 2 and involves a sequence of 1) probe-only (A), 2) masker-followed-by-probe (B), and 3) masker-only (C) stimuli. The probe-only condition (A) yields the desired neural response plus an artifact from the probe. The masker-and-probe condition (B) with an appropriate masker advance yields stimulus artifacts from both masker and probe; the neural responses to the probe are absent or diminished because of forward masking. The masker-only condition (C) yields only the masker artifact. By using the subtraction method $(\mathrm{A}-[\mathrm{B}-\mathrm{C}])$ to cancel the large masker stimulus artifacts found in each condition, one can extract the relatively small neural response.

The main aim of this study was to validate the NRT measurements and the software with adult users of the Nucleus 24 cochlear implant and to determine the major test parameters necessary to maximize the chances for recording an ECAP. The NRT stimulation parameters on 1 electrode pair are illustrated in Fig

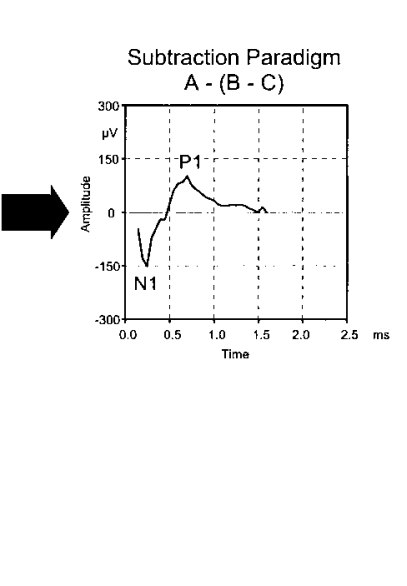

Fig 2. Subtraction method for reducing masker stimulus artifact. Stimulation signals from buffers $\mathrm{A}, \mathrm{B}$, and $\mathrm{C}$ and their respective responses are shown on left, and subtraction paradigm $(\mathrm{A}-[\mathrm{B}-$ C]) with resultant enhanced neural response is shown on right. First negative peak is labeled N1, and following positive peak is labeled P1. Ampitude of neural response is defined as N1-P1 peakto-peak amplitude.
3. The specific test (stimulation and recording) parameters investigated in this study included 1) stimulation mode (wide bipolar or monopolar); 2) measurement delay (time period between the end of the probe stimulus and the start of the measurement: 35 to $150 \mu \mathrm{s}$ ); 3) stimulation rate (number of stimulus pulses per second: 80 or $35 \mathrm{~Hz}$ ); 4) number of sweeps (number of averaged responses: 50,100, or 200); 5) masker level (stimulation level of the masker stimulus); and 6) masker advance (time interval between the end of the masker stimulus and the onset of the probe stimulus).

\section{METHOD}

A total of 38 users of the Nucleus CI24M cochlear implant (21 men and 17 women; age range, 24 to 75 years; mean age, 50.5 years) from 5 European cochlear implant centers participated in the study. Each subject had to have a minimum of 18 intracochlear electrodes and be willing to participate in the trial. No subjects were excluded from this study on the

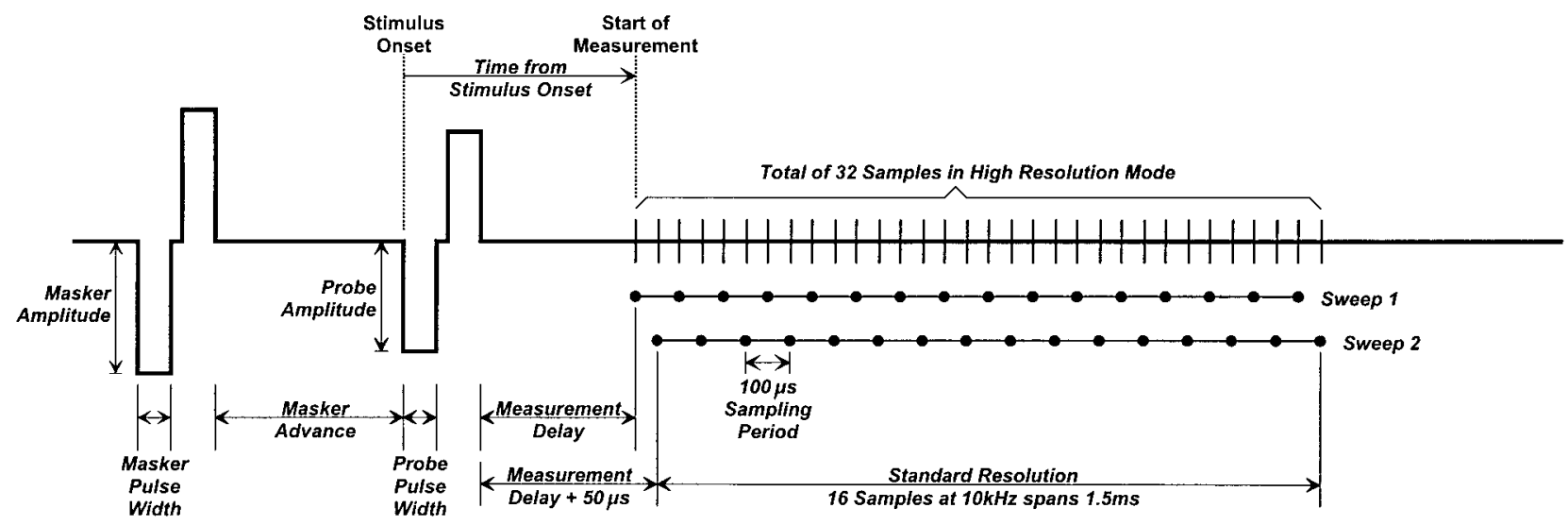

Fig 3. Diagram of NRT parameters shows masker amplitude, masker pulse width, masker advance, probe amplitude, probe pulse width, measurement delay, and sampling period. In standard resolution, 16 samples at $10 \mathrm{kHz}$ spanning $1.5 \mathrm{~ms}$ are captured. In high-resolution mode, 2 sweeps of 16 samples, each offset by $50 \mu \mathrm{s}$, are recorded and interlaced to form single data set. Time axis origin is at probe stimulus onset. 
TABLE 1. SUMMARY OF SUBJECT DATA AND MEASUREMENT RESULTS

\begin{tabular}{|c|c|c|c|c|c|c|c|c|}
\hline \multirow[b]{2}{*}{ Subject* } & \multirow[b]{2}{*}{ Sex } & \multirow[b]{2}{*}{$\begin{array}{c}\text { Age (y) } \\
\text { at Testing }\end{array}$} & \multirow[b]{2}{*}{$\begin{array}{c}\text { Cause of Hearing } \\
\text { Impairment }\end{array}$} & \multicolumn{5}{|c|}{ Neural Response } \\
\hline & & & & $\begin{array}{c}\text { Electrode } \\
20\end{array}$ & $\begin{array}{c}\text { Electrode } \\
15\end{array}$ & $\begin{array}{c}\text { Electrode } \\
10\end{array}$ & $\begin{array}{c}\text { Electrode } \\
5\end{array}$ & $\begin{array}{c}\text { Electrode } \\
1\end{array}$ \\
\hline $\mathrm{F} 1$ & $\mathrm{~F}$ & 29 & Ototoxicity & Yes & DNT & Yes & DNT & Yes \\
\hline $\mathrm{F} 2$ & M & 43 & Progressive loss & No & DNT & No & DNT & No \\
\hline F3 & $\mathrm{F}$ & 44 & Progressive loss & No & DNT & No & DNT & No \\
\hline F4 & $\mathrm{F}$ & 49 & Progressive loss & Yes & DNT & Yes & DNT & Yes \\
\hline F5 & $\mathrm{F}$ & 49 & Progressive loss & No & DNT & No & DNT & No \\
\hline F6 & M & 61 & Sudden loss & Yes & DNT & Yes & DNT & Yes \\
\hline F7 & $\mathrm{M}$ & 62 & Progressive loss & Yes & DNT & Yes & DNT & Yes \\
\hline F8 & $\mathrm{M}$ & 69 & Sudden loss & No & DNT & Yes & DNT & Yes \\
\hline H1 & $\mathrm{F}$ & 67 & Progressive loss & DNT & DNT & Yes & DNT & Yes \\
\hline $\mathrm{H} 2$ & M & 42 & Meningitis & Yes & Yes & Yes & Yes & Yes \\
\hline $\mathrm{H} 3$ & M & 64 & Progressive loss & Yes & Yes & Yes & Yes & Yes \\
\hline $\mathrm{H} 4$ & $\mathrm{~F}$ & 24 & Progressive loss & No & Yes & Yes & Yes & Yes \\
\hline H5 & M & 45 & Sudden loss & DNT & DNT & No & DNT & No \\
\hline H6 & $\mathrm{M}$ & 63 & Scarlet fever & No & DNT & No & No & No \\
\hline $\mathrm{H} 7$ & M & 64 & Progressive loss & Yes & DNT & Yes & DNT & Yes \\
\hline $\mathrm{K} 1$ & $\mathrm{M}$ & 25 & Unknown & Yes & Yes & Yes & Yes & Yes \\
\hline $\mathrm{K} 2$ & M & 40 & Unknown & Yes & Yes & Yes & Yes & Yes \\
\hline $\mathrm{K} 3$ & $\mathrm{~F}$ & 41 & Meningitis & DNT & DNT & Yes & DNT & DNT \\
\hline $\mathrm{K} 4$ & M & 55 & Unknown & Yes & Yes & Yes & Yes & Yes \\
\hline K5 & $\mathrm{F}$ & 56 & Unknown & Yes & Yes & Yes & Yes & Yes \\
\hline K6 & $\mathrm{M}$ & 64 & Unknown & Yes & Yes & Yes & Yes & Yes \\
\hline K7 & $\mathrm{M}$ & 58 & Unknown & Yes & Yes & Yes & Yes & Yes \\
\hline K8 & M & 75 & Unknown & Yes & Yes & Yes & Yes & Yes \\
\hline L1 & $\mathrm{F}$ & 43 & Progressive loss & Yes & Yes & Yes & Yes & Yes \\
\hline L2 & $\mathrm{M}$ & 43 & Progressive loss & No & Yes & Yes & Yes & Yes \\
\hline L3 & M & 57 & Progressive loss & No & No & No & No & No \\
\hline L4 & $\mathrm{M}$ & 61 & Progressive loss & Yes & Yes & Yes & Yes & Yes \\
\hline $\mathrm{Z1}$ & $\mathrm{F}$ & 42 & Progressive loss & Yes & Yes & Yes & Yes & Yes \\
\hline $\mathrm{Z} 2$ & $\mathrm{~F}$ & 51 & Progressive loss & Yes & Yes & Yes & Yes & Yes \\
\hline $\mathrm{Z3}$ & $\mathrm{F}$ & 28 & Progressive loss & Yes & Yes & Yes & Yes & No \\
\hline $\mathrm{Z} 4$ & $\mathrm{~F}$ & 45 & Sudden loss & Yes & Yes & Yes & Yes & Yes \\
\hline $\mathrm{Z} 5$ & $\mathrm{~F}$ & 62 & Progressive loss & Yes & Yes & Yes & Yes & Yes \\
\hline Z6 & $\mathrm{M}$ & 72 & Progressive loss & No & Yes & Yes & Yes & Yes \\
\hline $\mathrm{Z7}$ & $\mathrm{F}$ & 58 & Progressive loss & Yes & Yes & Yes & Yes & Yes \\
\hline $\mathrm{Z8}$ & M & 52 & Progressive loss & Yes & Yes & Yes & Yes & Yes \\
\hline Z9 & $\mathrm{M}$ & 37 & Progressive loss & Yes & Yes & Yes & No & DNT \\
\hline $\mathrm{Z10}$ & $\mathrm{F}$ & 37 & Progressive loss & Yes & Yes & Yes & Yes & Yes \\
\hline Z11 & $\mathrm{F}$ & 43 & Progressive loss & Yes & Yes & Yes & No & No \\
\hline
\end{tabular}

DNT — did not test.

*Subjects are identified by letter identifying test center (F - Freiburg, $\mathrm{H}$ - Hannover, $\mathrm{K}-\mathrm{Kiel}, \mathrm{L}-\mathrm{Lund}$, Z - Zürich) and sequential number for each center.

basis of any other criterion apart from age or consent to participate. The details (gender, age, and cause of hearing impairment) of the subjects included in this study are summarized in Table 1.

The NRT measurements in all of the test centers were completed after operation with the same NRT v1.04 software and similar test setups consisting of a personal computer, IF5 interface card, processor control interface, SPrint speech processor, and CI24M cochlear implant system as shown in Fig 1. The implant has 22 intracochlear electrodes, 1 extracochlear ball electrode on a flying lead placed under the temporalis muscle (MP1), and a plate electrode on the receiver-stimulator (MP2). Measurements were made for each subject at different stimulation-recording sites along the electrode array, as summarized in Table 2. Wide bipolar, as well as monopolar, stimulation modes were initially investigated (Brown et $\mathrm{al}^{4}$ ) with a subset of the subjects. For the recording, the mono- 
TABLE 2. ELECTRODE CONFIGURATIONS TESTED

\begin{tabular}{cccc}
\hline \hline $\begin{array}{c}\text { Stimulating } \\
\text { Electrode }\end{array}$ & $\begin{array}{c}\text { Indifferent } \\
\text { Electrode }\end{array}$ & $\begin{array}{c}\text { Recording } \\
\text { Electrode }\end{array}$ & $\begin{array}{c}\text { Indifferent } \\
\text { Electrode }\end{array}$ \\
\hline 10 & 20 & 15 & MP2 \\
20 & 10 & 15 & MP2 \\
$1 *$ & $11 \dagger$ & $6 \ddagger$ & MP2 \\
$1 *$ & MP1 & $3 \S$ & MP2 \\
5 & MP1 & 7 & MP2 \\
10 & MP1 & 12 & MP2 \\
15 & MP1 & 17 & MP2 \\
20 & MP1 & 22 & MP2 \\
$*$ Or most basal possible. & & \\
$\dagger$ Stimulating electrode +10. & & \\
$\ddagger$ Stimulating electrode +5. & & \\
$\S$ Stimulating electrode +2. & & \\
\hline
\end{tabular}

polar mode was chosen because it had been shown to give the largest response amplitudes in a preliminary pilot study. For bipolar stimulation modes, the active recording electrode was selected to be in the middle between the 2 bipolar stimulation electrodes. For the monopolar stimulation mode, the active recording electrode was selected to be 2 electrodes more apical of the active stimulation electrode. Individual centers investigated the effects of different test parameters described above (stimulation rate, number of sweeps, measurement delay, masker level, and masker advance).

\section{RESULTS}

In general, all of the centers were able to obtain a reliable response with NRT across a variety of cochlear implant users (Table 1) under different measurement conditions. Neural responses could be obtained from 31 of the 38 subjects $(81.6 \%)$ and on 132 of the total of 160 electrodes tested $(82.5 \%)$.

Figure 4 shows a typical amplitude growth series indicating how the neural response changes with the stimulation level. The first negative peak (N1) of the neural response occurs approximately between 200 and $300 \mu$ s after the stimulus onset, followed by the first positive peak (P1), occurring at approximately $700 \mu$ s after the stimulus onset. The response amplitude is defined as the peak-to-peak amplitude from $\mathrm{N} 1$ to P1. Plotting the change in response amplitude as a function of the stimulation level yields the amplitude growth function (AGF).

Data comparing wide-bipolar versus monopolar stimulation were initially collected from 15 subjects. Neural responses were obtained from 13 of these subjects. Comparison of the AGFs from bipolar and monopolar mode stimulation showed that in the majority of cases ( 10 of the 13 subjects; 76.9\%), monopolar stimulation produced larger neural responses than equivalent wide-bipolar stimulation, as illustrated by the example in Fig 5. All subsequent results

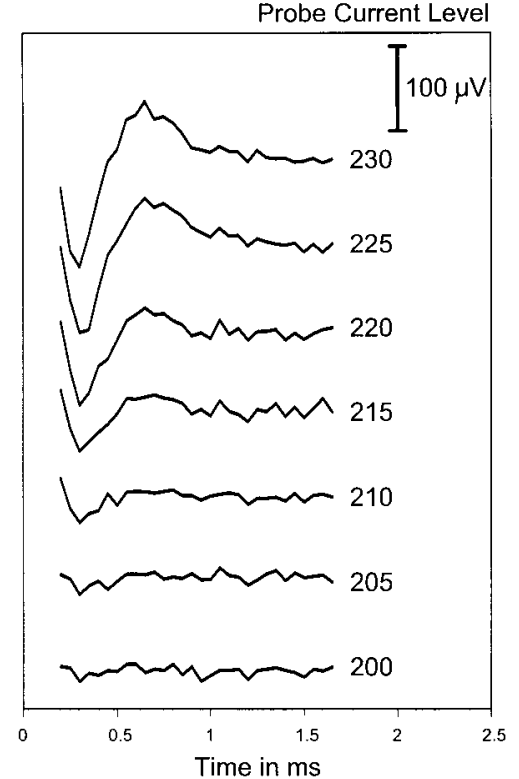

Fig 4. Typical series of neural responses recorded with NRT v1.04 software. In this example, monopolar stimulation was presented on electrode 1 (indifferent electrode MP1) and recorded from electrode 3 (indifferent electrode MP2). Probe current level varied from 230 to 200 CL (current levels; internal units of Nucleus CI24M cochlear implant), while masker current level was fixed at $230 \mathrm{CL}$. Note that time axis origin corresponds to time of probe stimulus onset.

were then based on the findings made in monopolar stimulation mode according to the electrode configurations shown in Table 2 .

The effect of varying the measurement delay was examined with 34 subjects. Six of these subjects yielded no neural responses. From the other 28 subjects, the results showed that shorter delays were more likely to result in overloading of the measurement amplifier, producing a distorted waveform (Fig $6 ; 46 \mu \mathrm{s}$ ). Increasing this delay reduces the likelihood of saturating the measurement amplifier, but excessive delays could result in missing early features of the waveform, such as the N1 peak (Fig 6; $84 \mu \mathrm{s}$ ). Careful adjustment of the delay parameter is required to produce a clear neural response (Fig 6; $70 \mu$ s). The optimal delay depends on the subject and the measurement amplifier gain selected, and it ranged between $35 \mu$ s and $100 \mu$ s for these 28 subjects.

Another way to avoid nonlinear operation of the measurement amplifier is to reduce the gain from 60 $\mathrm{dB}$ to $40 \mathrm{~dB}$. The recordings for 10 subjects that showed amplifier saturation effects at $60-\mathrm{dB}$ measurement amplifier gain were improved when the gain was lowered to $40 \mathrm{~dB}$, thereby yielding clear neural responses even with a short delay.

A comparison of 2 stimulation rates $(35 \mathrm{~Hz}$ and $80 \mathrm{~Hz}$ ) was carried out in 31 subjects, and an example is shown in Fig 7. No significant difference in the 


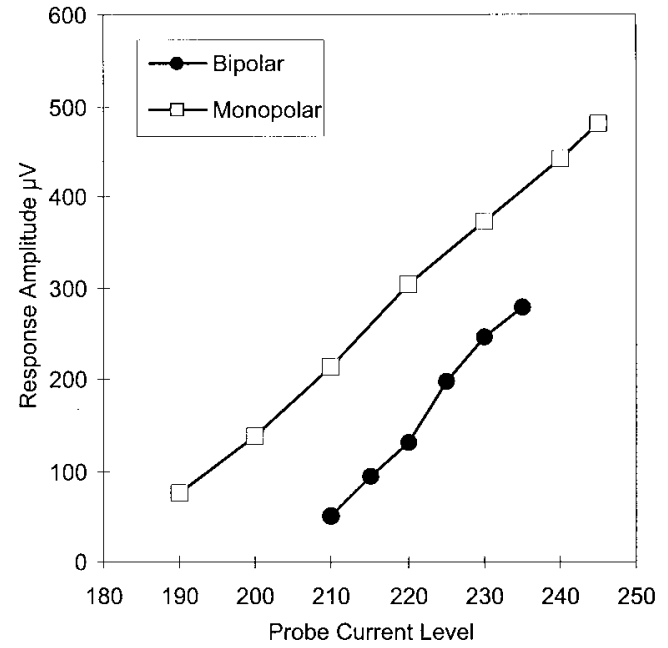

Fig 5. Example of amplitude growth functions comparing neural responses from bipolar versus monopolar stimulation. In this instance, stimulation active electrode was 10 , and indifferent electrode was either 20 (bipolar) or MP1 (monopolar; see Table 2). In 10 of 13 subjects, neural responses to monopolar stimulation were larger than bipolar counterpart at same stimulation level.

resulting neural response was found between the 2 stimulation rates in all 31 cases. Also, for a given stimulation level, the perceived loudness was found to be softer, to various degrees, at the lower stimulation rate in all cases.

Excellent recordings of the ECAP have been obtained by averaging over only a small number of

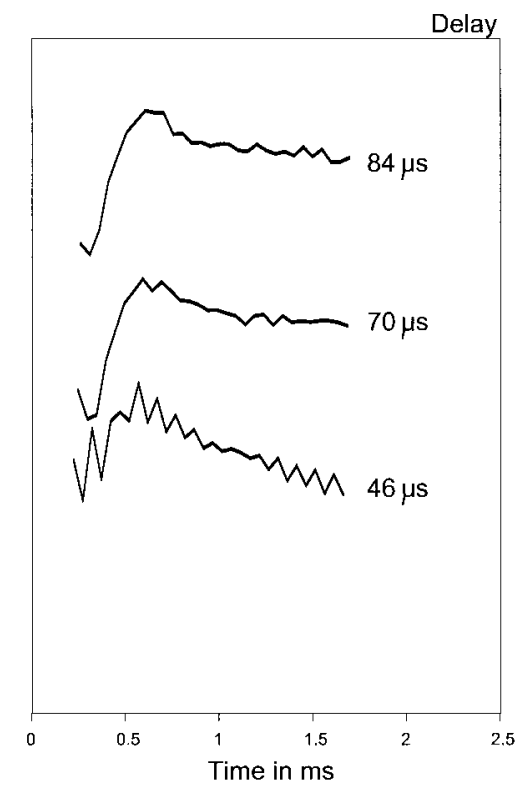

Fig 6. Effect of variations of measurement delay on same electrode with all other test parameters kept constant. Jagged waveform at $46 \mu$ s indicates nonlinear saturation behavior of measurement amplifier. Longer delays restore linear behavior of amplifier. Increasing delay indefinitely would eventually result in not capturing N1 peak. In this example, measurement delay of $70 \mu$ s produces best neural response.

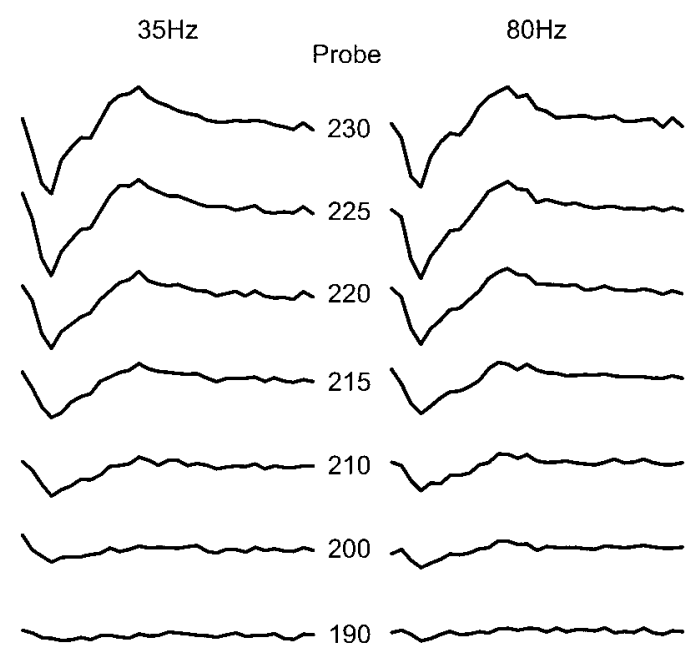

Fig 7. Comparison of 2 stimulation rates, $35 \mathrm{~Hz}$ and 80 $\mathrm{Hz}$, with all other test parameters kept constant. Choice of stimulation rate has no effect on recorded neural response.

sweeps (Fig 8). Data from 19 subjects investigated all showed that at $60 \mathrm{~dB}$ of gain, as the number of sweeps was increased, the relative noise in the recording improved. Beyond 100 sweeps, there is little subjective improvement in the quality of the response waveform. At 40-dB gain, 200 sweeps were necessary to obtain a clear neural response.

The effect of the masker level was also investigated in 13 subjects, and an example typical of all 13 subjects is shown in Fig 9. The neural responses on the left in Fig 9 were measured with a fixed masker at

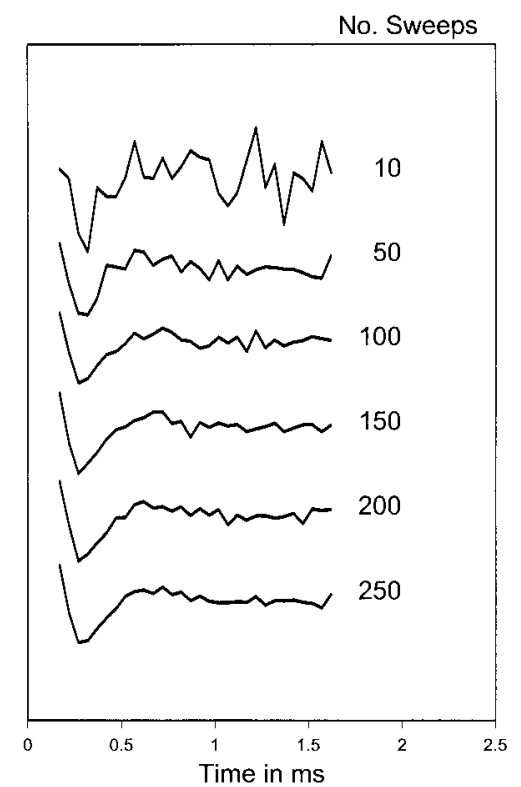

Fig 8. Effect of variations of number of sweeps across which measurements are averaged from 10 to 250 sweeps, with all other test parameters kept constant and measurement amplifier gain set to $60 \mathrm{~dB}$. Increasing number of sweeps improves signal-to-noise ratio. Beyond 100 sweeps, there is little improvement in quality of recorded waveform. 


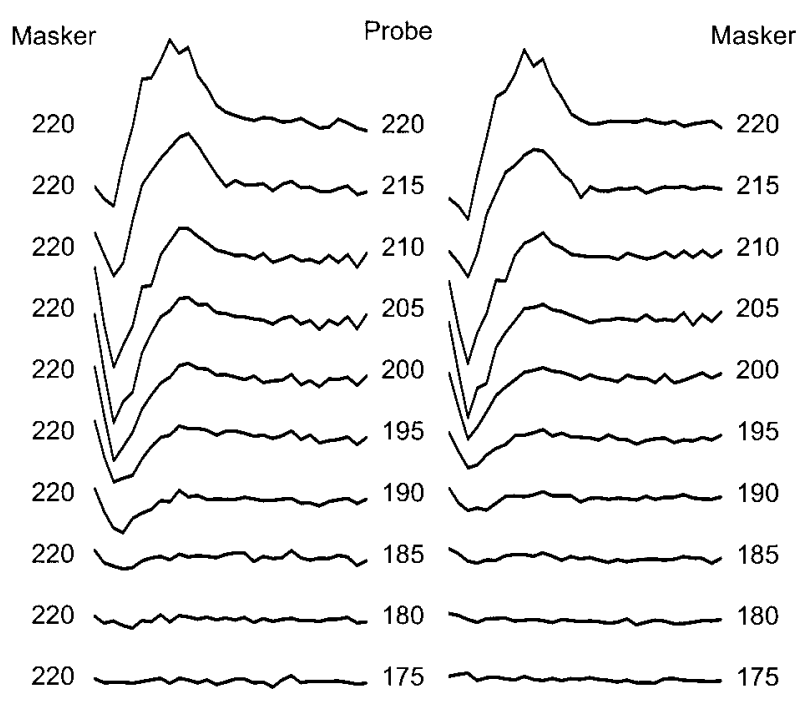

Fig 9. Comparison between NRT measurements recorded with fixed high masker level (left) and responses with masker level that was varied with probe stimulus level (right). Note that on left, clearly defined N1 is seen at probe level of 190 CL. On right, similar N1 response is seen at probe level of $195 \mathrm{CL}$.

the highest acceptable presentation level, and the responses on the right were recorded with a masker set to the same level as the probe stimulus level. The responses obtained with the fixed high masker level (set at the loudest acceptable presentation level for the NRT stimulus) show a lower neural response threshold than do the responses obtained with the masker level set to be the same as the probe level. The paradigm in which the masker and probe varied together was preferred by the subjects, because they were not always presented with a continuously loud signal during the measurement, as the stimulation level was varied. Although it was not the preferred condition, all subjects found the fixed high masker level acceptable.

The effect of the masker advance was examined with 22 subjects. Figure 10 illustrates how the response amplitude typically varies as the masker advance is increased from $125 \mu$ s to $2,500 \mu \mathrm{s}$. The NRT response amplitude increases with increasing masker advance up to approximately $500 \mu \mathrm{s}$, at which the largest response amplitude was recorded. The amplitude then decreases markedly with longer masker advance intervals. Note that the chart is plotted on a $\log -\log$ scale.

Only 7 of the 38 subjects tested demonstrated no neural response on any of the selected test electrodes with this technique.

\section{DISCUSSION}

The ability to record neural responses in $82.5 \%$ of the tested electrodes ( $81.6 \%$ of the subjects) supports the validity of the NRT system for measuring ECAPs

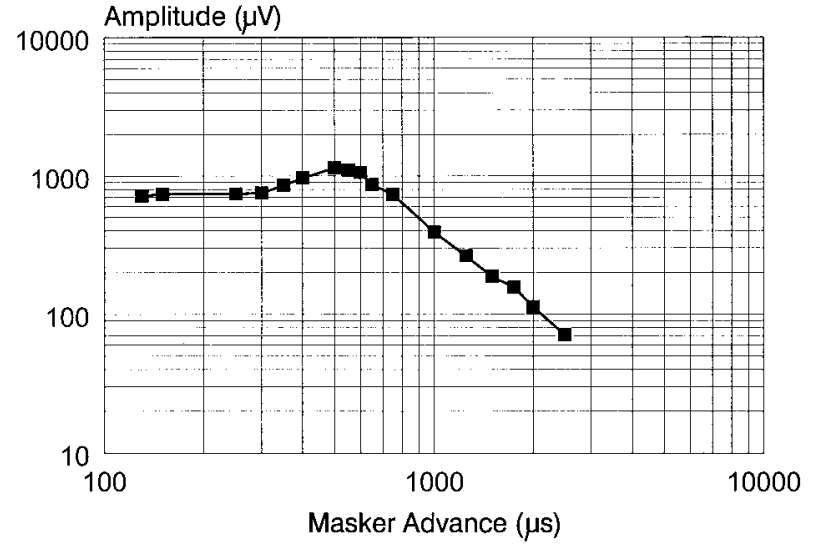

Fig 10. Effect of masker advance on neural response amplitude for intervals from 150 to $4,000 \mu \mathrm{s}$. Largest response amplitude occurs around masker advance of 500 $\mu \mathrm{s}$.

in adult subjects. Variability in response waveforms and response amplitudes across subjects and different stimulation and recording sites, which may be dependent on physiological factors such as cause of hearing impairment, local nerve survival, ${ }^{5-7}$ or location of stimulation and recording electrodes within the scala tympani, can only be properly evaluated after test parameters have been appropriately optimized.

The measurement delay, the gain of the measurement amplifier, the masker level, and the masker advance were shown to have an effect on the ability to obtain a neural response in an individual cochlear implant user, and therefore optimization of the test parameters was important to obtaining a repeatable response.

Varying the measurement delay parameter essentially changes the time window used to capture the neural response. Nonlinear behavior of the measurement amplifier would introduce distortions to the neural response. The measurement delay is needed in order to prevent the very large stimulus artifacts accompanying the neural response from driving the amplifier into nonlinear operation. The measurement delay, however, should be kept as short as possible in order to capture the N1 peak. The absence of the N1 peak would compromise estimates of the response amplitude. Thus, there is a tradeoff between being able to capture the neural response as early as possible and avoiding nonlinear operation of the amplifier. The delay parameter therefore needs to be carefully adjusted to obtain a clear neural response.

Related to the issue of avoiding nonlinear behavior of the measurement amplifier is the gain setting of the amplifier. A smaller gain is less likely to result in saturation of the amplifier. However, for a given amount of internal measurement noise, the signalto-noise ratio at $40-\mathrm{dB}$ gain is obviously poorer than 
at $60 \mathrm{~dB}$, and more averaging, and consequently a longer measurement time, is then required to get rid of the accompanying noise. As a shorter measurement time is generally more desirable, a default gain of 60 $\mathrm{dB}$ should be used whenever possible. A 40-dB gain should be selected if optimization of the measurement delay at $60 \mathrm{~dB}$ of gain fails to produce a clear neural response.

The use of a fixed high masker level produces a more accurate record of the neural response, primarily because of the forward-masking nature of the subtraction paradigm. Ideally, the subtraction paradigm requires that the stimulated neurons be fully refractory from the masker so that there is no neural response to the subsequent probe signal in the maskerand-probe condition (Fig 2, measurement B). If there is insufficient forward masking, the remnant neural response evoked by the probe signal will result in a reduction of the resultant response amplitude after the subtraction. This effect is seen in Fig 9, in which the response amplitude falls off more rapidly when the masker is not kept at a fixed high level.

The masker advance is also a crucial parameter in ensuring that the subtraction paradigm works as it is meant to. The optimal amount of forward masking appears to occur at around $500 \mu$ s of masker advance. With longer masker advances, the reduction in forward masking results in an underestimation of the response amplitude due to the subtraction paradigm. At shorter masker advances, however, the reduction in the response amplitude cannot be a result of insufficient forward masking. Instead, it is probably a result of the neural response to the masker stimulus encroaching into the measurement window. This would, again, result in an underestimation of the actual neural response amplitude.

The results suggest that the stimulation rates tested have little or no effect on the measured neural response. All clinicians preferred the faster rate $(80$ $\mathrm{Hz}$ maximum), as this reduced the overall test time. That the perceived loudness decreases with decreasing stimulation rate indicates that some temporal integration effects are present. This finding implies that the stimulation rate parameter may be reduced to achieve a higher stimulation level without raising the perceived loudness of the test signal.

The minimum number of sweeps required to obtain a clear neural response is expected to be subjectdependent, but is primarily determined by the amount of accompanying noise in the measurement. In instances in which the neural response amplitude is very large compared to the measurement noise, very few sweeps are needed to capture the neural response. However, this is rarely the case, particularly when one is attempting to measure lower response amplitudes, and some averaging is required. With the amplifier gain set to $60 \mathrm{~dB}$, it was found that 100 sweeps were usually sufficient to yield a clear neural response. At an amplifier gain of $40 \mathrm{~dB}$, the minimum number of sweeps needs to be approximately doubled to 200 sweeps to compensate for the reduced signal-to-noise ratio.

A set of default test parameters has therefore been established. A stimulation rate of $80 \mathrm{~Hz}$ is preferred over $35 \mathrm{~Hz}$, as little detrimental effect was found on the resultant response, and the overall test time was reduced. A test parameter series using a measurement amplifier gain of $60 \mathrm{~dB}, 100$ sweeps, a fixed masker level equal to the highest acceptable presentation lev$\mathrm{el}$, and a masker advance of $500 \mu \mathrm{s}$ has been shown to provide the quickest, most reliable results in the majority of adults tested.

After the above parameters have been set, some other test parameters must still be optimized for individual subjects and electrodes in order to capture a clearly defined neural response waveform. These include the measurement delay and, in some cases, the amplifier gain and stimulation rate. Further background details that are useful for performing parameter optimization with the NRT software have been described by $\mathrm{Lai}^{8}$ and are also treated by Abbas et al. ${ }^{9}$

One point noted during the course of the study was that in a number of cases, no neural responses could be obtained, even at the highest acceptable presentation level with the default parameters. However, when the stimulation rate was reduced from 80 $\mathrm{Hz}$ to $35 \mathrm{~Hz}$, the perceived loudness of the test signals decreased. This reduction, in turn, allowed the stimulation level to be increased before the highest acceptable presentation level was reached at the lower stimulation rate. At higher stimulation levels, the neural response begins to appear. The implication here is that a certain amount of synchronicity in the neural firing needs to be present before the neural response can be recorded via NRT. It is therefore conceivable that in instances in which subjects have a low subjective threshold, the level of synchronous activity is insufficient for NRT to register the neural response. The mechanism behind this observation is currently under investigation.

Possible reasons for the lack of a recordable response in a small number of cases ( 7 of 38 subjects) include test parameters that may not have been fully optimized, excessively high electrical impedance of the stimulating or recording electrodes, a presentation level that was not adequate to elicit a synchronous neural response, or other physiological factors. All 
of the above findings need to be considered in the development of common protocols for future investigations.

\section{CONCLUSION}

\section{Neural response telemetry provides a unique meth-}

od to assess peripheral neural function in Nucleus CI24M users. The NRT measurement technique has been shown to be viable for recording the ECAP or neural response. A set of default test parameters has been established to provide a relatively quick method of measuring the ECAP in the majority of subjects.

ACKNOWLEDGMENT — The authors acknowledge Denise Cafarelli Dees, Cochlear (UK) Ltd, for her invaluable contributions in the preparation of this manuscript.

\section{REFERENCES}

1. Spoendlin H, Schrott A. Quantitative evaluation of the human cochlear nerve. Acta Otolaryngol Suppl (Stockh) 1990 (suppl 470):61-70.

2. Carter PM, Fisher AR, Nygard TM, et al. Monitoring the electrically evoked compound action potential by means of a new telemetry system. Ann Otol Rhinol Laryngol Suppl 1995; 104(suppl 166):48-51.

3. Brown CJ, Abbas PJ, Gantz B. Electrically evoked wholenerve action potentials: data from human cochlear implant users. J Acoust Soc Am 1990;88:1385-91

4. Brown CJ, Abbas PJ, Borland J, Bertschy MR. Electrically evoked whole nerve action potentials in Ineraid cochlear implant users: responses to different stimulating electrode configurations and comparison to psychophysical responses. J Speech Hear Res 1996;39:453-67.
5. Smith L, Simmons FB. Estimating eighth nerve survival by electrical stimulation. Ann Otol Rhinol Laryngol 1983;92: 19-23.

6. Hall RD. Estimation of surviving spiral ganglion cells in the deaf rat using the electrically evoked auditory brainstem response. Hear Res 1990;45:123-36.

7. Jyung RW, Miller JM, Cannon SC. Evaluation of eighth nerve integrity by the electrically evoked middle latency response. Otolaryngol Head Neck Surg 1989;101:670-82.

8. Lai WK. An NRT cookbook. Basel, Switzerland: Cochlear AG, 1999.

9. Abbas PJ, Brown CJ, Shallop JK, et al. Summary of results using the Nucleus CI24M implant to record the electrically evoked compound action potential. Ear Hear 1999;20:45-59. 